\title{
Quality control of solar radiation data within the South African Weather Service solar radiometric network
}

\author{
Lucky Ntsangwane ${ }^{1,2^{*}}$, Brighton Mabasa ${ }^{1}$, Venkataraman Sivakumar $^{2}$, \\ Nosipho Zwane ${ }^{1}$, Katlego Ncongwane ${ }^{1}$, Joel Botai ${ }^{1}$ \\ ${ }^{1}$ South African Weather Service, 01 Eco park Drive, Eco glades Block B, Cnr Olievenhoutbosch and Ribbon \\ Grass Street, Centurion, Pretoria, South Africa \\ ${ }^{2}$ Discipline of Physics, School of Chemistry and Physics, University of KwaZulu Natal, Private Bag X54001, \\ Durban 4001, South Africa. \\ L. Ntsangwane - http://orcid.org/0000-0002-8071-5115 B. Mabasa - https://orcid.org/0000-0002-0354-9811 \\ V. Sivakumar-https://orcid.org/0000-0003-2462-681X N. Zwane-https://orcid.org/0000-0003-3517-0408 \\ K. Ncongwane - https://orcid.org/0000-0002-3923-1530 J. Botai - https://orcid.org/0000-0003-4355-0662
}

\begin{abstract}
This study reports on the performance results of the Baseline Surface Radiation Network (BSRN) quality control procedures applied to the solar radiation data, from September 2013 to December 2017, within the South African Weather Service radiometric network. The overall percentage performance of the SAWS solar radiation network based on BSRN quality control methodology was 97.79\%, 93.64\%, 91.60\% and 92.23\% for long wave downward irradiance (LWD), global horizontal irradiance (GHI), diffuse horizontal irradiance (DHI) and direct normal irradiance (DNI), respectively, with operational problems largely dominating the percentage of bad data. The overall average performance of the surface solar radiation dataset - Heliosat data records for the GHI estimation for all stations showed a mean bias deviation of $8.28 \mathrm{Wm}^{-2}$, a mean absolute deviation of $9.06 \mathrm{Wm}^{-2}$ and the root mean square deviation of $11.02 \mathrm{Wm}^{-2}$. The correlation, quantified by the square of correlation coefficient $\left(R^{2}\right)$, between ground-based and Heliosat-derived GHI time series was $\sim 0.98$. The established network has the potential to provide high quality minute solar radiation data sets (GHI, DHI, DNI and LWD) and auxiliary hourly meteorological parameters vital for scientific and practical applications in renewable energy technologies.
\end{abstract}

Keywords: Baseline Surface Radiation Network, performance results, satellite-retrieved irradiance, ground stations, global horizontal irradiance

\section{Highlights}

- Atmospheric conditions inadvertently influence the quality of ground-based measurements of solar irradiances.

- $\quad$ South African Weather Service's solar resource database exhibits good quality and has both scientific and practical applications.

- $\quad$ Satellite-derived irradiance compares favourably with ground measurements across South African Weather Service's solar radiation network.

Journal of Energy in Southern Africa 30(4): 51-63

DOI: https://dx.doi.org/10.17159/2413-3051/2019/v30i4a5586

Published by the Energy Research Centre, University of Cape Town ISSN: 2413-3051

This work is licensed under a Creative Commons Attribution-ShareAlike 4.0 International Licence https://journals.assaf.org.za/jesa

Sponsored by the Department of Science and Technology

\footnotetext{
*Corresponding author: +27 (0)12 367 6239; email: lucky.ntsangwane@weathersa.co.za
} 


\section{Introduction}

Knowledge of the local solar radiation arriving at the surface of Earth is very important for many different applications, such as crop growth models, architectural designs, planning, designing and sizing of solar energy systems $[1,2,3]$. To be successful in these applications, solar radiation measurements are required at strategic sites [1]. Historically, solar radiation data has been measured and recorded by the national meteorological services around the world [4]. Until recently, the South African Weather Service (SAWS) has been the primary source of ground-based solar radiation data in South Africa [5, 6]. The old solar radiometric network, which was operational from 1957 to 1997, collapsed because of technical difficulties and lack of maintenance [5, 7]. Owing to the rapid development of solar-based renewable energy technologies and projects, the demand for reliable and accurate data for site-specific solar resource assessment has increased [4]. Quality control (QC) may be a tedious process and, as a result, most users are keen to use data directly from meteorological services with confidence without performing an additional and fine data check [8]. To this end, in 2013, the SAWS re-established the national solar radiometric network, comprising thirteen new stations within the country's six climatic zones [9]. These stations are equipped with robust and reliable instruments suitable for Baseline Surface Radiation Network (BSRN) solar radiation measurements [10]. Climatic zones are regions with similar climatic conditions [11] and, according to Conradie [9], they were established to classify different areas based on their maximum energy demand and maximum energy consumption. Where each radiometric station is located, there is an automatic weather station (AWS) measuring hourly temperature, rainfall, pressure, humidity, wind speed and wind direction to provide auxiliary meteorological parameters. Measurements of solar radiation are more susceptible to errors than other meteorological parameters [12]. According to Urraca et al. [12], there are two major sources of these errors related to ground-based solar radiation measurements: equipment and operational errors. Equipment errors are inherent to the type and construction of the sensors used in the measuring campaign $[4,8]$. Solar measuring sensors produce electric current when reacting with radiation, which is converted into measurement of solar radiation. Solar radiation measurement instruments are also prone to change in sensitivity, thermal offsets, spectral effects, geometry and the environment [4]. On the other hand, operational errors are independent of the type of sensor, and involve different factors such as shading by nearby objects or dust covering the dome of the sensor, incorrect levelling, station shut-downs, and electric fields near cables or a malfunction in the data-logger. Careful selection of the place to install the station, as well as a regular maintenance, can ameliorate most of these operational errors. Applying a QC procedure becomes an essential step before using ground-based datasets $[4,8]$ to identify and quantify all the different types of errors in the measurements of solar radiation. According to Huld et al. [13], accurate and reliable solar radiation measurements provide investmentgrade bankable solar radiation data to the solar energy industry, project developers, decision makers in financing and policy-making institutions, and the scientific community. Accurate ground-based solar radiation data is also important for the improvement and validation of satellite-derived solar radiation data and scientific models.

In the present study, the BSRN QC procedures were applied to the solar radiation data within the SAWS radiometric network, with data coverage from September 2013 to December 2017.

\section{Material and methods}

\subsection{Ground-based solar radiation data}

The datasets used in this study consist of ground measurements registered at thirteen stations in South Africa, owned and maintained by the SAWS. They are evenly distributed in six different climatic regions [11] over an area bounded by latitudes $23^{\circ}$ to $34^{\circ}$ south and longitudes $18^{\circ}$ to $31^{\circ}$ east, Figure 1. The elevation of the stations ranges from $80 \mathrm{~m}$ to almost $1700 \mathrm{~m}$, as described in Table 1.

Table 2 provides information on the manufacturer and type of instruments used at the measurement stations. De Aar, located in the Northern Cape, is a BSRN station utilising two ventilated CMP21 pyranometers by Kipp \& Zonen, which are rated in the highest possible International Organization for Standardization pyranometer performance category. The ventilation units keep the pyranometer's domes clean from frost and water. Periodical maintenance procedures are applied to the various instruments to satisfy the BSRN quality requirements. The ground-based solar radiation database contains one-minute values of all the measured parameters at each station.

\subsection{Satellite-derived solar radiation data}

The surface solar radiation dataset - Heliosat (SARAH) [18] is part of the climate data records produced by Satellite Application Facility on Climate Monitoring (CMSAF), where the objective is to produce a temporally homogeneous data record for long times suitable for climate analysis, i.e., assessment of anomalies and trends. The SARAH data records are derived using data from the Meteosat visible infra-red imager instruments of the Meteosat First Generation satellites (Meteosat 2-7) up to the 


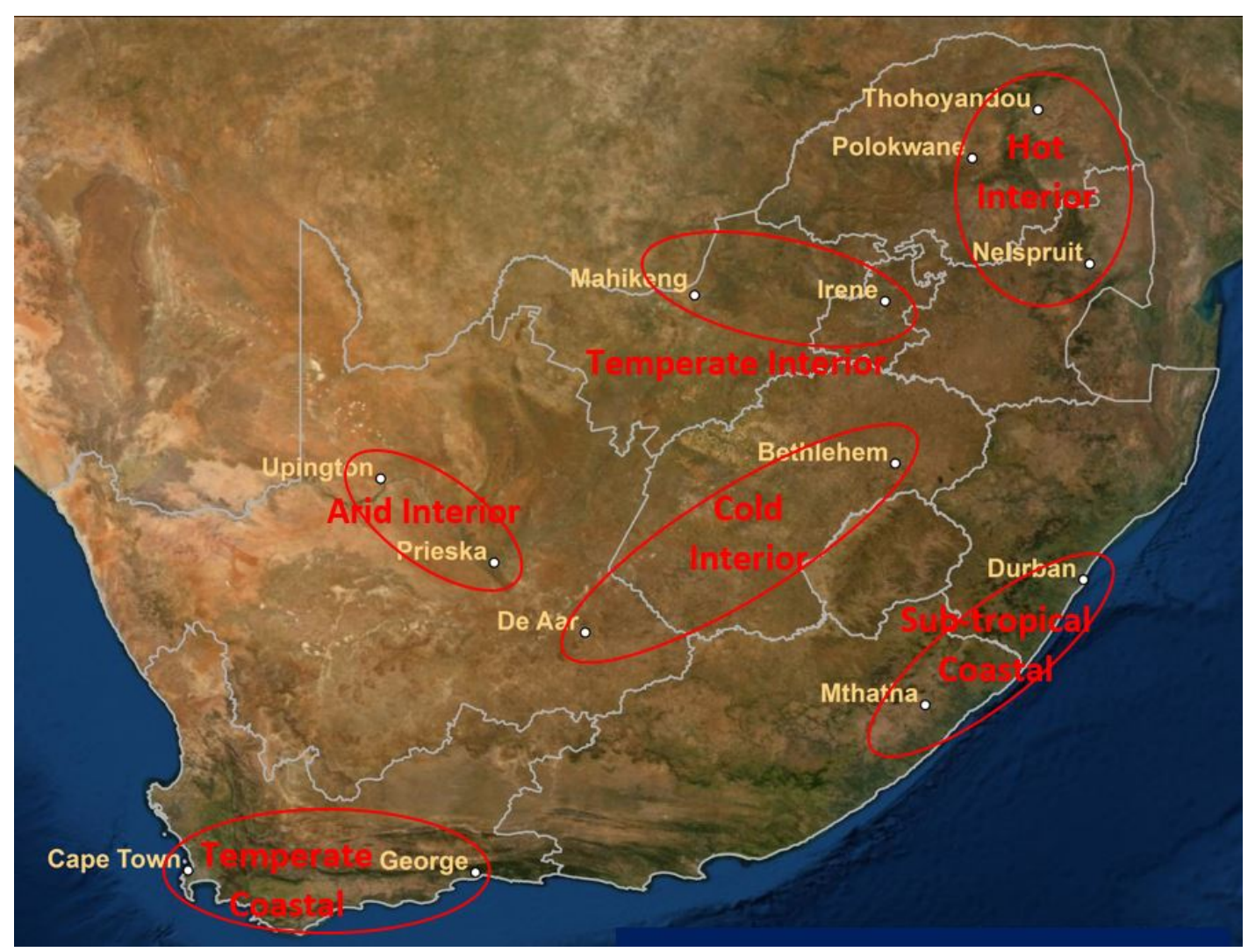

Figure 1: Location of the thirteen considered stations and the six climatic regions (Hot interior, Temperate interior, Arid interior, Cold interior, Sub-tropical coastal and Temperate coastal).

Table 1. Coordinates of the considered stations in South Africa. The length of the time series, in months, is also indicated, along with the starting date of the dataset registered at every station.

\begin{tabular}{lccccc}
\hline \multicolumn{1}{c}{ Station } & Latitude & Longitude & Altitude & Data coverage & Climatic zone \\
\hline & $(\text { S, positive })^{*}$ & $(\text { E, positive })^{*}$ & $(\mathrm{~m})$ & & \\
\hline Prieska & -29.68 & 22.71 & 989 & $2013-09$ to 2015-08 & Arid interior \\
Upington & -28.48 & 21.12 & 848 & $2014-02$ to 2017-12 & Arid interior \\
De Aar & -30.67 & 23.99 & 1284 & $2014-05$ to 2017-12 & Cold interior \\
Irene & -25.91 & 28.21 & 1524 & $2014-03$ to 2017-12 & Temperature interior \\
Nelspruit & -25.39 & 31.10 & 870 & $2014-05$ to 2017-12 & Hot interior \\
Mahikeng & -25.81 & 25.54 & 1289 & $2014-08$ to 2017-12 & Temperature interior \\
Mthatha & -31.55 & 28.67 & 744 & $2014-07$ to 2017-12 & Subtropical coastal \\
Bethlehem & -28.25 & 28.33 & 1688 & $2015-01$ to 2017-12 & Cold interior \\
Cape Point & -34.35 & 18.48 & 86 & $2015-01$ to 2017-12 & Temperature coastal \\
George & -34.01 & 22.38 & 192 & $2015-01$ to 2017-12 & Temperature coastal \\
Durban & -29.61 & 31.11 & 91 & $2015-03$ to 2017-12 & Subtropical coastal \\
Polokwane & -23.86 & 29.45 & 1233 & $2015-03$ to 2017-12 & Temperature interior \\
Thohoyandou & -23.08 & 30.38 & 619 & $2015-03$ to 2017-10 & Hot interior \\
\hline S = South; E = East & & & & & \\
\hline
\end{tabular}


Table 2. Solar radiation and meteorological parameter instrument manufacturer, type and uncertainty [10].

\begin{tabular}{|c|c|c|c|}
\hline Manufacturer & Type and uncertainty & Parameter & Station \\
\hline Kipp \& Zonen & Solys 2 Sun Tracker & Track the sun & All stations \\
\hline Kipp \& Zonen & $\begin{array}{l}\text { CHP1 Pyrheliometer }(0.5 \% \text { or } 1.5 \\
\text { Wm-2) }\end{array}$ & Direct normal irradiance & All stations \\
\hline Kipp \& Zonen & $\begin{array}{l}\text { CMP11 (no. 1: Sun) Pyranometer } \\
(2 \% \text { or } 5 \mathrm{Wm}-2)\end{array}$ & $\begin{array}{l}\text { Global horizontal } \\
\text { irradiance }\end{array}$ & $\begin{array}{l}\text { All stations except } \\
\text { for De Aar }\end{array}$ \\
\hline Kipp \& Zonen & $\begin{array}{l}\text { CMP11 (no. } 2: \text { Shaded) Pyranome- } \\
\text { ter }(2 \% \text { or } 3 \mathrm{Wm}-2)\end{array}$ & $\begin{array}{l}\text { Diffuse horizontal } \\
\quad \text { irradiance }\end{array}$ & $\begin{array}{l}\text { All stations except } \\
\text { for De Aar }\end{array}$ \\
\hline Kipp \& Zonen & $\begin{array}{l}\text { CMP21 (no. 1: Sun) Pyranometer } \\
(2 \% \text { or } 5 \mathrm{Wm}-2)\end{array}$ & $\begin{array}{l}\text { Global horizontal } \\
\text { irradiance }\end{array}$ & Only at De Aar \\
\hline Kipp \& Zonen & $\begin{array}{c}\text { CMP21 (no. } 1 \text { : Shaded) Pyranome- } \\
\text { ter }(2 \% \text { or } 3 \mathrm{Wm}-2)\end{array}$ & $\begin{array}{l}\text { Diffuse horizontal } \\
\text { irradiance }\end{array}$ & Only at De Aar \\
\hline Kipp \& Zonen & $\begin{array}{l}\text { CGR4 Pyrgeometer ( } 2 \% \text { or } \\
\qquad 3 \mathrm{Wm}-2)\end{array}$ & Long-wave irradiance & Only at De Aar \\
\hline Kipp \& Zonen & CUV-5 & $\begin{array}{l}\text { UV radiation (290-385 } \\
\text { nm) }\end{array}$ & Only at Prieska \\
\hline Kipp \& Zonen & UVS-AB-T & UV-A \& UV-B & $\begin{array}{l}\text { All stations except } \\
\text { for Prieska }\end{array}$ \\
\hline Vaisala & Barometer PTB110 & Pressure & All stations \\
\hline RM Young Wind Sensor & Model 05103 & Wind & All stations \\
\hline $\begin{array}{l}\text { Rotronic temperature } \\
\text { and humidity probe }\end{array}$ & HC2-S3 & $\begin{array}{l}\text { Humidity and } \\
\text { temperature }\end{array}$ & All stations \\
\hline \multicolumn{4}{|c|}{ UV = ultraviolet, UV-A = ultraviolet A, UV-B = ultraviolet B } \\
\hline
\end{tabular}

end of 2005 and from the spinning enhanced visible and infra-red imager (SEVIRI) instruments on the Meteosat second generation (MSG) (Meteosat 8-10) satellites thereafter. The SARAH provides data for the GHI and DNI irradiance at the earth surface from 1983 to date at high temporal (down to 30 minutes, but also daily and monthly averages) and spatial $\left(0.05^{\circ} \times 0.05^{\circ}\right)$ resolutions. Surface solar radiation is obtained using a modified Heliosat method to calculate the effective cloud albedo and the Specmagic clear-sky model [14], which is an extension to spectral bands of the mesoscale atmospheric irradiance code model [15]. The Specmagic uses monthly average values of atmospheric water vapour content from the European Centre for Medium-Range Weather Forecasts Reanalysis (ERAinterim) product and long-term monthly climatologies of aerosol optical depth based on monitoring atmospheric composition and climate [16, 17]. Validation of SARAH, using high-quality ground stations from international networks, e.g., BSRN, http://bsrn.awi.de, as well as from national networks, has been published [18-21]. At present, the SARAH dataset provided by CMSAF exists in two versions. The dataset used in the present work is based on version 1 of SARAH, with one difference: the hourly data used here are calculated from one satellite image per hour. In contrast, the SARAH version 1 data available from CMSAF use a weighted average of three half-hourly satellite images to calculate the hourly solar radiation values.

\subsection{Methods for quality control and validation}

\subsubsection{Quality control of solar radiation data}

The schematic diagram illustrating the methodology considered in the present study is given in Figure 2 .

According to Urraca et al. [20], there are several and diverse QC methods applied to solar radiation data by different meteorological services and independent researchers. The SAWS has preferred to use well-known QC procedures from the BSRN [22]. These QC procedures mark those samples identified out of the normal test limits of data and usually leave the decision of removing marked cases to the user. In this study, the BSRN QC procedures with three levels of testing was applied on the archived monthly minute data stored in a central 


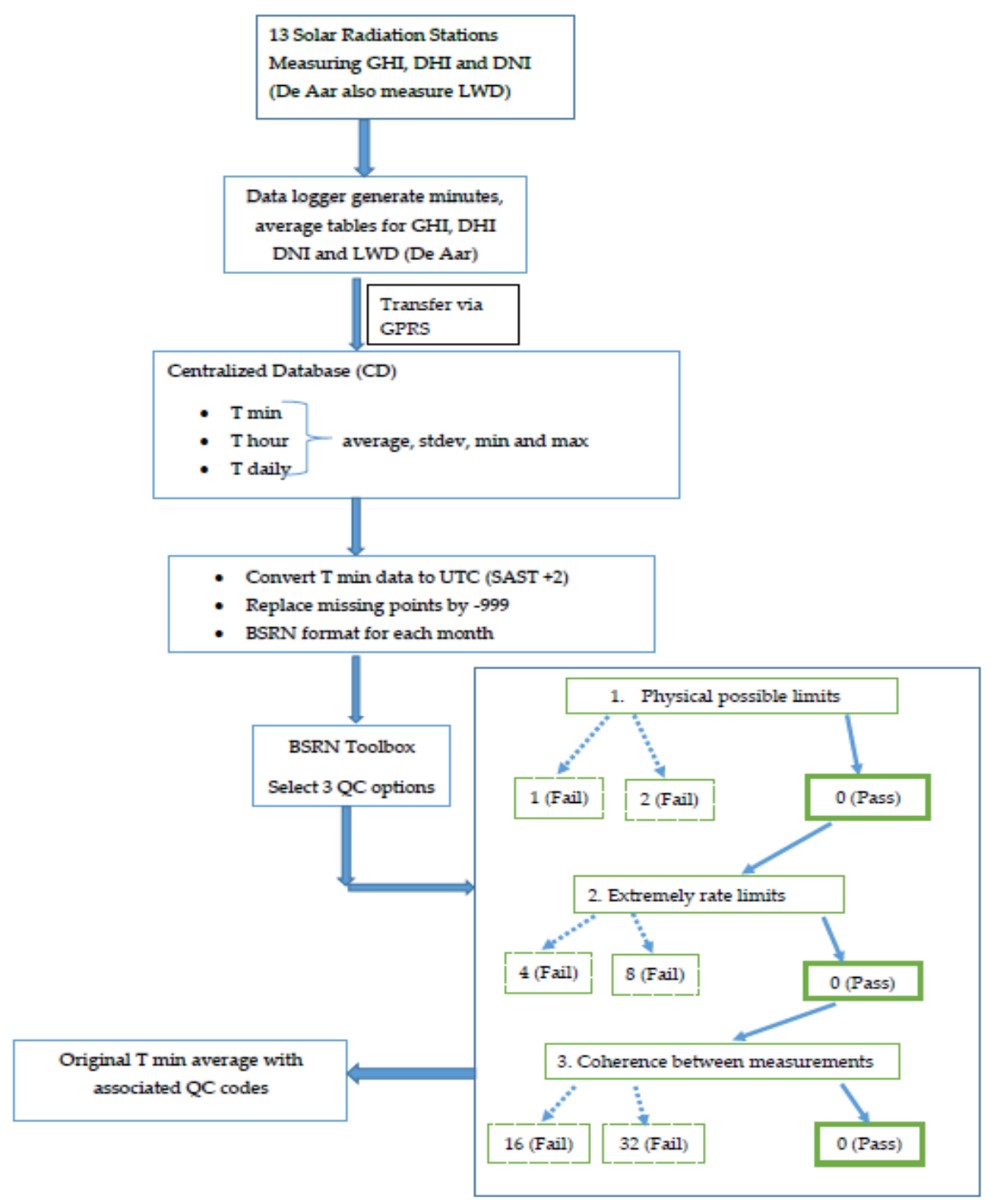

Figure 1: Flow chart of the quality control applied to South African Weather Services solar radiation data, where $\mathrm{GHI}=$ global horizontal irradiance, $\mathrm{DHI}=$ diffuse horizontal irradiance, $\mathrm{DNI}=$ direct normal irradiance, $L W D=$ long-wave downward irradiance, GPRS = general packet radio service, T = time, UTC = Coordinated Universal Time, BSRN = Baseline Surface Radiation Network, $\mathrm{QC}=$ quality control.

database. Each point minute data is associated with its own quality code (see Table 3) after the test. These tests can be classified in three major categories: physical possible limits, extremely rare limits, and coherence between measurements or across quantities relationships, which can be defined as follows.

- Physical possible limits: check for possible physical reasonable maximum and minimum values. These extremal values are assigned codes 1 and 2 corresponding to less than a minimum and greater than maximum reasonable values, respectively $[12,22]$. Data that did not pass this test is flagged and excluded from further analysis.

- Extremely rare limits: check the data that is in the physical possible limit range for random errors often associated to unusual weather conditions like multiple reflection between broken clouds and the snow surface or a track- 
ing problem (hardware). Typical tracking problems experienced at some of the stations, include, power failures due to damaged electric cables and overcharging batteries. Moreover, mechanical damage to the tracking instrument was experienced, resulting from severe thunderstorms, wind and hail. Therefore, data that is beyond the extremely rare cases should at least be visually inspected and, if no physical reasons is found, it is excluded from the analysis.

- Coherence between measurements: compared measurements or across quantity relationships are based on the relationship among the three main solar radiation parameters: GHI, DHI, and DNI. In cases where GHI and DHI are almost the same, most of the values do not pass the coherence quality test. This usually happens when the DHI sensor was exposed to the sun, thus recording similar values as GHI, resulting from a tracking problem. Data that does not pass this test is flagged and excluded from further analysis.

Table 3. Description of quality control (QC) flags for South African Weather Service solar radiation data. The flag numbers are a summation of all three QC stages; and each one indicates a stage where the data failed the QC test [22].

\begin{tabular}{|c|c|}
\hline $\begin{array}{l}\text { Flag } \\
\text { no. }\end{array}$ & Description \\
\hline 0 & Good quality, passed all three QC tests \\
\hline 5 & $\begin{array}{l}\text { Missing data (placeholder -999 when } \\
\text { archiving) }\end{array}$ \\
\hline 8 & Data is above extremely rare limits \\
\hline 10 & $\begin{array}{l}\text { Data is above physical possible and } \\
\text { extremely rare limits }\end{array}$ \\
\hline 16 & Data is below compared measurement \\
\hline 24 & $\begin{array}{l}\text { Data is above extremely rare limits (coded } \\
\text { as } 8 \text { ) }\end{array}$ \\
\hline 26 & $\begin{array}{l}\text { Data is above physical possible and } \\
\text { extremely rare limits (coded as 10) }\end{array}$ \\
\hline 32 & Data is above compared measurement \\
\hline 40 & $\begin{array}{l}\text { Data is above extremely rare limits and } \\
\text { compared measurement }\end{array}$ \\
\hline 42 & $\begin{array}{l}\text { Data is above physical possible, extremely } \\
\text { rare limits and compared measurement }\end{array}$ \\
\hline
\end{tabular}

The minute ground-based solar radiation data of GHI, DHI, DNI and LWD from all thirteen SAWS solar radiometric stations (Table 1), were subjected to quality check procedures based on BSRN
QC standards $[22,23,24]$ before the validation was performed. Only the data that passed the first two quality check tests (physically possible limits and extremely rare limits) was used in the validation. Files containing missing values and the data that did not pass the first two BSRN QC tests were flagged and later replaced by not a number (NaN) before that timestamp was considered for the validation $[22,23,24]$. Moreover, the minute values were averaged to 15 minutes and then four slots of 15-minute averages were averaged to get hourly mean values $[23,24]$. Furthermore, all night values, values between sunset (20:00) and sunrise (05:00) based on South African standard time, i.e., when the solar zenith angle is less than $90^{\circ}$, were replaced by 0 . Hourly mean values were then averaged to get daily mean values and, subsequently, monthly mean values calculated from the daily mean values.

\subsubsection{Validation of the satellite-based solar radiation}

Quality controlled irradiance values in the validation of satellite-based models involved a comparison of computed monthly mean satellite-retrieved estimates with monthly averaged ground-based solar radiation data. The CMSAF-SARAH monthly mean surface incoming shortwave radiation data with a spatial resolution of $0.05^{\circ} \times 0.05^{\circ}$ from MSG was validated against concurrent quality-checked monthly average GHI values calculated from minute GHI values measured from thirteen SAWS solar radiometric network. According to Schulz et al. [25], the CMSAF-SARAH products are accurate enough to be used for solar energy applications and to support meteorological organisation with diurnal, sub-seasonal and seasonal solar radiation data sets.

\section{Validation metrics}

The validation metrics, including the mean bias deviation (MBD), mean absolute deviation (MAD), root mean square deviation (RMSD) and the square of correlation coefficient $\left(\mathrm{R}^{2}\right)$, were calculated from all the months with $90 \%$ or more [19] data that passed the quality tests. In addition, calculations were made for diffuse fraction (DHI/GHI) and clearness index (GHI/top of atmosphere), hereafter referred to as DF and $\mathrm{K}_{\mathrm{T}}$, respectively. The DF and $\mathrm{K}_{\mathrm{T}}$ were calculated for all thirteen stations from the months with $90 \%$ or more [19] of both GHI and DHI data that passed the quality tests. Annual average temperature and humidity levels of each station from 2013 to 2017 were also calculated for each radiometric station, using hourly data from AWS. Satellite-retrieved and groundbased solar radiation values of GHI were compared at the different stations for every year and month 
independently. The MBD, RMSD and MAD in absolute $\left(\mathrm{Wm}^{-2}\right)$ values were computed according to Equations 1 to $3[3,26,27]$. In addition to these, the $R^{2}$ correlation coefficient was also calculated using Equation $4[26,27]$.

$$
\begin{aligned}
& M B D=\frac{1}{N} \sum_{i=1}^{N}\left(G_{i}^{S}-G_{i}^{m}\right) \\
& R M S D=\sqrt{\frac{1}{N} \sum_{i=1}^{N}\left(G_{i}^{S}-G_{i}^{m}\right)^{2}} \\
& M A D=\frac{1}{N} \sum_{i=1}^{N}\left|G_{i}^{S}-G_{i}^{m}\right| \\
& R^{2}=1-\frac{\sum_{i=1}^{N}\left(G_{i}^{m}-G_{i}^{S}\right)}{\sum_{i=1}^{N}\left(G_{i}^{m}-\overline{G^{m}}\right)^{2}}
\end{aligned}
$$

where $G_{i}^{s}$ is the satellite-retrieved irradiance value at the $i^{\text {th }}$ time point and $G_{i}^{m}$ is the ground-based solar radiation value for that timestamp; $N$ is the total number of points considered in the period of time analysed (year or month); and $\overline{G^{m}}$ is the average ground-based solar radiation value during the considered time.

\section{Results and discussion \\ 3.1 The BSRN quality control}

The BSRN QC results are presented in Tables 4 and 5 , where the overall percentage performance of SAWS' solar radiation network based on BSRN QC procedures was $97.79 \%, 93.64 \%, 91.6 \%$ and $92.23 \%$ for LWD, GHI, DHI and DNI respectively. Operational problems dominated the percentage of bad data as follows: LWD 2.21\%, GHI 1.6\%, DHI $3.57 \%$ and DNI $3.57 \%$. Only data represented by code 0 was regarded as having passed all the three BSRN QC tests and, thus, representing the overall percentage performance. Code 5 represents missing data or data that was not recorded, which is indicative of overall percentage of the operational problems and errors. On the other hand, codes 8 and 10 represent data that failed first and second BSRN QC tests respectively. All the irradiance data sets passed the first QC test and only $0.3 \%$ of GHI and DHI data failed the second QC test. Code 16 and 32 represent data that failed the third BSRN QC test, with the results showing that at least $4 \%$ of GHI, $4.3 \%$ of DHI and $4.2 \%$ of DNI failed the measurement coherence test between them. Code 40 represents data that failed both the second and third BSRN QC test and code 42 represents data that failed all three BSRN QC tests. For the validation, the data coded 0 were used. This data was re- garded as good quality because it passed all quality tests and useable. On the other hand, data bearing the codes 5, 8, 10, 16, 32, 40 and 42 was discarded, replaced by $\mathrm{NaN}$, and was not considered for further analysis in the validation because it failed either of the three quality tests. The final volume of monthly data used at every station depended on the QC results of the measured values. Riihela et al. [19] advocate validating satellite products against in situ measurements with more than $90 \%$ of good quality data.

\subsection{Validation of the satellite-derived solar radiation product}

Considering the results obtained in all the stations, the overall average performance of the SARAH data record for the GHI estimation showed an MBD of 8.28 $\mathrm{Wm}^{-2}$, MAD of $9.06 \mathrm{Wm}^{-2}$ and RMSD of 11.02 $\mathrm{Wm}^{-2}$. Analysing the correlation between groundbased and satellite-derived GHI time series with the $\mathrm{R}^{2}$ coefficient, the average performance of the SARAH satellite product in the estimation of the GHI values was $\sim 0.98$. Table 6 presents the absolute average MBD, RMSD and MAD values obtained from the validation of the complete valid time series of the SARAH GHI estimates at every station. Besides the $\mathrm{R}^{2}$ coefficient, the number of months used at every location is also indicated.

From the validation of the global irradiance estimates, the SARAH product provided accurate estimates of the monthly average GHI values in every location other than Durban and Cape Point, where it also showed the highest overestimation. This overestimation at these locations could indicate either a problem with the ground measurements or a misinterpretation of the input parameters, such as aerosols or albedo, used by the satellite method [29]. In addition, low altitudes, $91 \mathrm{~m}$ and $86 \mathrm{~m}$, respectively, may have exacerbated the overestimation.

According to Posselt et al. [28], the validation accuracy threshold for MAD of monthly mean GHI against SARAH monthly mean GHI ought to be 15 $\mathrm{Wm}^{-2}$, target accuracy threshold is $10 \mathrm{Wm}^{-2}$ and optimal accuracy threshold is $8 \mathrm{Wm}^{-2}$. The comparison between concurrent SARAH GHI against SAWS GHI monthly means showed a great similarity with MAD of less than $15 \mathrm{Wm}^{-2}$ in 11 of 13 stations. Figure 3 shows only Cape Point (temperature coastal) and Durban (subtropical coastal) stations had an MAD greater than the validation threshold accuracy of $15 \mathrm{Wm}^{-2}$, recording $18.9 \mathrm{Wm}^{-2}$ and $19.0 \mathrm{Wm}^{-2}$, respectively.

Prieska, Upington, De Aar, Irene, Mafikeng, Bethlehem, Polokwane (stations located in the arid climatic regions, cold interior and temperature interior) reached an optimal threshold with a MAD of 
Table 4. Weighted averages of all Baseline Surface Radiation Network - quality control codes for global horizontal irradiance, diffuse horizontal irradiance and direct normal irradiance, respectively, per station from when the station started recording a full month of data to end of December 2017.

\begin{tabular}{|c|c|c|c|c|c|c|c|c|c|c|c|c|c|c|c|c|c|c|c|c|c|c|c|c|}
\hline \multirow{2}{*}{$\begin{array}{l}\text { Parameter } \\
\text { Code/Sta- } \\
\text { tion }\end{array}$} & \multicolumn{8}{|c|}{ Global horizontal irradiance } & \multicolumn{8}{|c|}{ Diffuse horizontal irradiance } & \multicolumn{8}{|c|}{ Direct normal irradiance } \\
\hline & 0 & 5 & 8 & 10 & 16 & 32 & 40 & 42 & 0 & 5 & 8 & 10 & 16 & 32 & 40 & 42 & 0 & 5 & 8 & 10 & 16 & 32 & 40 & 42 \\
\hline Prieska & 96.91 & 2.79 & 0.0 & 0.0 & 0.0 & 0.27 & 0.00 & 0 & 96.77 & 2.79 & 0.15 & 0.01 & 0.17 & 0.03 & 0.01 & 0.00 & 96.85 & 2.79 & 0.07 & 0.01 & 0.26 & 0.02 & 0 & 0.00 \\
\hline Upington & 97.29 & 1.61 & 0.0 & 0.0 & 0.7 & 0.41 & 0.00 & 0 & 97.20 & 1.61 & 0.06 & 0.06 & 0.39 & 0.68 & 0.01 & 0.00 & 97.23 & 1.57 & 0.17 & 0.00 & 0.29 & 0.54 & 0 & 0.00 \\
\hline De Aar & 97.02 & 2.13 & 0.0 & 0.0 & 0.0 & 0.80 & 0.00 & 0 & 97.02 & 2.24 & 0.21 & 0.01 & 0.79 & 0.05 & 0.01 & 0.00 & 96.79 & 2.13 & 0.21 & 0.00 & 0.79 & 0.06 & 0 & 0.00 \\
\hline Irene & 96.89 & 0.02 & 0.1 & 1.2 & 0.8 & 0.54 & 0.14 & 0 & 96.93 & 0.02 & 0.20 & 1.04 & 0.89 & 0.79 & 0.00 & 0.00 & 96.86 & 0.02 & 1.39 & 0.00 & 0.87 & 0.79 & 0 & 0.00 \\
\hline Nelspruit & 93.45 & 0.01 & 0.1 & 0.8 & 0.1 & 5.58 & 0.02 & 0 & 93.42 & 0.01 & 0.08 & 1.24 & 5.14 & 0.08 & 0.00 & 0.01 & 93.64 & 0.01 & 0.70 & 0.00 & 5.56 & 0.10 & 0 & 0.00 \\
\hline Mahikeng & 94.86 & 0.04 & 0.2 & 0.8 & 0.4 & 3.62 & 0.05 & 0 & 94.80 & 0.04 & 0.27 & 0.83 & 3.72 & 0.40 & 0.00 & 0.00 & 95.10 & 0.04 & 0.83 & 0.00 & 3.74 & 0.38 & 0 & 0.00 \\
\hline Mthatha & 99.16 & 0.01 & 0.0 & 0.0 & 0.2 & 0.60 & 0.02 & 0 & 99.16 & 0.06 & 0.02 & 0.00 & 0.60 & 0.21 & 0.00 & 0.00 & 99.15 & 0.00 & 0.02 & 0.00 & 0.62 & 0.21 & 0 & 0.00 \\
\hline Bethlehem & 94.70 & 0.12 & 0.1 & 0.9 & 0.7 & 3.31 & 0.14 & 0 & 92.12 & 2.12 & 1.51 & 1.06 & 3.45 & 0.65 & 0.07 & 0.01 & 94.74 & 0.12 & 1.00 & 0.01 & 3.45 & 0.71 & 0 & 0.00 \\
\hline Cape Point & 92.37 & 3.13 & 0.0 & 0.0 & 0.3 & 4.17 & 0.03 & 0 & 90.56 & 3.13 & 1.77 & 0.02 & 4.19 & 0.28 & 0.02 & 0.00 & 92.38 & 3.13 & 0.04 & 0.00 & 3.60 & 0.26 & 0 & 0.00 \\
\hline George & 84.07 & 2.85 & 0.1 & 0.0 & 2.5 & 11.32 & 0.04 & 0 & 83.81 & 5.47 & 0.38 & 0.01 & 11.6 & 1.23 & 1.12 & 0.01 & 84.00 & 5.63 & 0.09 & 0.00 & 11.45 & 2.35 & 0 & 0.00 \\
\hline Durban & 95.59 & 0.01 & 0.0 & 0.0 & 1.5 & 2.87 & 0.00 & 0 & 74.98 & 20.64 & 0.08 & 0.00 & 2.87 & 1.51 & 0.00 & 0.01 & 75.70 & 20.00 & 0.0 & 0.00 & 2.86 & 1.43 & 0 & 0.00 \\
\hline Polokwane & 84.12 & 2.32 & 0.0 & 0.2 & 0.5 & 7.26 & 0.10 & 0 & 83.64 & 2.32 & 0.66 & 0.09 & 7.44 & 0.46 & 0.00 & 0.00 & 84.06 & 2.32 & 0.25 & 0.00 & 7.44 & 2.28 & 0 & 0.00 \\
\hline Thohoyandou & 90.84 & 5.61 & 0.0 & 0.0 & 4.9 & 1.16 & 0.00 & 0 & 90.41 & 6.00 & 0.01 & 0.00 & 1.60 & 4.46 & 0.00 & 0.00 & 92.70 & 6.00 & 0.00 & 0.00 & 1.21 & 1.64 & 0 & 0.01 \\
\hline Overall & 93.6 & 1.59 & 0 & 0.3 & 1 & 3.22 & 0.04 & 0 & 91.6 & 3.57 & 0.42 & 0.34 & 3.29 & 0.83 & 0.1 & 0.01 & 92.23 & 3.37 & 0.37 & 0 & 3.24 & 0.83 & 0 & 0.01 \\
\hline
\end{tabular}

Table 5. Weighted averages of all Baseline Surface Radiation Network - quality control codes

for long wave downward irradiance at De Aar from February 2014 to end of December 2017.

\begin{tabular}{ccccccccc}
\hline Parameter & \multicolumn{7}{c}{ Long-wave downward irradiance } \\
\hline Code/Station & 0 & 5 & 8 & 10 & 16 & 32 & 40 & 42 \\
\hline De Aar & 97.79 & 2.21 & 0 & 0 & 0 & 0 & 0 & 0 \\
Overall & 97.79 & 2.21 & 0 & 0 & 0 & 0 & 0 & 0 \\
\hline
\end{tabular}


Table 6. Results from the validation of the global horizontal irradiance estimates retrieved from the Surface Solar Radiation Dataset - Heliosat, which are comparable to other countries.

\begin{tabular}{|c|c|c|c|c|c|c|c|c|}
\hline Station & $\begin{array}{c}\text { Latitude } \\
\text { (S, positive) }\end{array}$ & $\begin{array}{c}\text { Longitude } \\
\text { (E, positive) }\end{array}$ & $\begin{array}{c}\text { Altitude } \\
\text { (m) }\end{array}$ & $\begin{array}{c}N \\
\text { (Months) }\end{array}$ & $\begin{array}{c}M B D \\
\left(W / m^{2}\right)\end{array}$ & $\begin{array}{c}M A D \\
\left(W / m^{2}\right)\end{array}$ & $\begin{array}{c}R M S D \\
\left(W / m^{2}\right)\end{array}$ & $r^{2}$ \\
\hline \multicolumn{9}{|c|}{ South African Weather Service current } \\
\hline Prieska & -29.68 & 22.71 & 989 & 22 & 4.2 & 4.2 & 5.4 & 0.998 \\
\hline Upington & -28.48 & 21.12 & 848 & 44 & -0.9 & 4.8 & 5.2 & 0.995 \\
\hline De Aar & -30.67 & 23.99 & 1284 & 40 & 0.8 & 3.6 & 4.6 & 0.997 \\
\hline Irene & -25.91 & 28.21 & 1524 & 41 & 6.9 & 7.8 & 10.0 & 0.981 \\
\hline Nelspruit & -25.39 & 31.10 & 870 & 42 & 8.9 & 9.0 & 11.4 & 0.958 \\
\hline Mahikeng & -25.81 & 25.54 & 1289 & 39 & 4.1 & 5.1 & 6.9 & 0.989 \\
\hline Mthatha & -31.55 & 28.67 & 744 & 41 & 10.3 & 10.3 & 12.1 & 0.982 \\
\hline Bethlehem & -28.25 & 28.33 & 1688 & 30 & 5.2 & 5.6 & 7.7 & 0.989 \\
\hline Cape Point & -34.35 & 18.48 & 86 & 29 & 18.9 & 18.9 & 21.5 & 0.991 \\
\hline George & -34.01 & 22.38 & 192 & 35 & 12.5 & 12.5 & 13.5 & 0.997 \\
\hline Durban & -29.61 & 31.11 & 91 & 23 & 19.0 & 19.0 & 20.1 & 0.981 \\
\hline Polokwane & -23.86 & 29.45 & 1233 & 29 & 7.4 & 7.6 & 11.6 & 0.964 \\
\hline Thohoyandou & -23.08 & 30.38 & 619 & 30 & 10.3 & 10.4 & 13.2 & 0.964 \\
\hline \multicolumn{9}{|c|}{ Spain } \\
\hline Almeria & 36.85 & -2.39 & & 12 & -5.4 & 7.5 & 9.8 & 0.990 \\
\hline Malaga & 36.72 & -4.48 & & 12 & -5.9 & 7.6 & 9.7 & 0.990 \\
\hline Bilbao & 43.17 & -2.91 & & 12 & 6.5 & 10.2 & 13.9 & 0.989 \\
\hline \multicolumn{9}{|c|}{ Sweden } \\
\hline Visby & 57.67 & 18.35 & & 212 & -4.7 & 5.8 & 7.7 & 0.890 \\
\hline Lund & 55.71 & 13.21 & & 222 & 0.8 & 5.0 & 7.1 & 0.900 \\
\hline Karlstad & 59.36 & 13.47 & & 214 & -3.3 & 4.9 & 7.0 & 0.900 \\
\hline \multicolumn{9}{|c|}{ Finland } \\
\hline Helski-Kumpula & 60.20 & 24.96 & & 35 & -5.5 & 6.4 & 8.0 & 0.900 \\
\hline Uto & 59.78 & 21.37 & & 97 & -8.1 & 8.2 & 10.1 & 0.920 \\
\hline
\end{tabular}

$\mathrm{S}=$ South, $\mathrm{E}=$ East $\mathrm{N}=$ number of months, $\mathrm{MBD}=$ mean bias deviation, $\mathrm{MAD}=$ mean absolute deviation, $\mathrm{RMSD}=$ root mean square deviation.

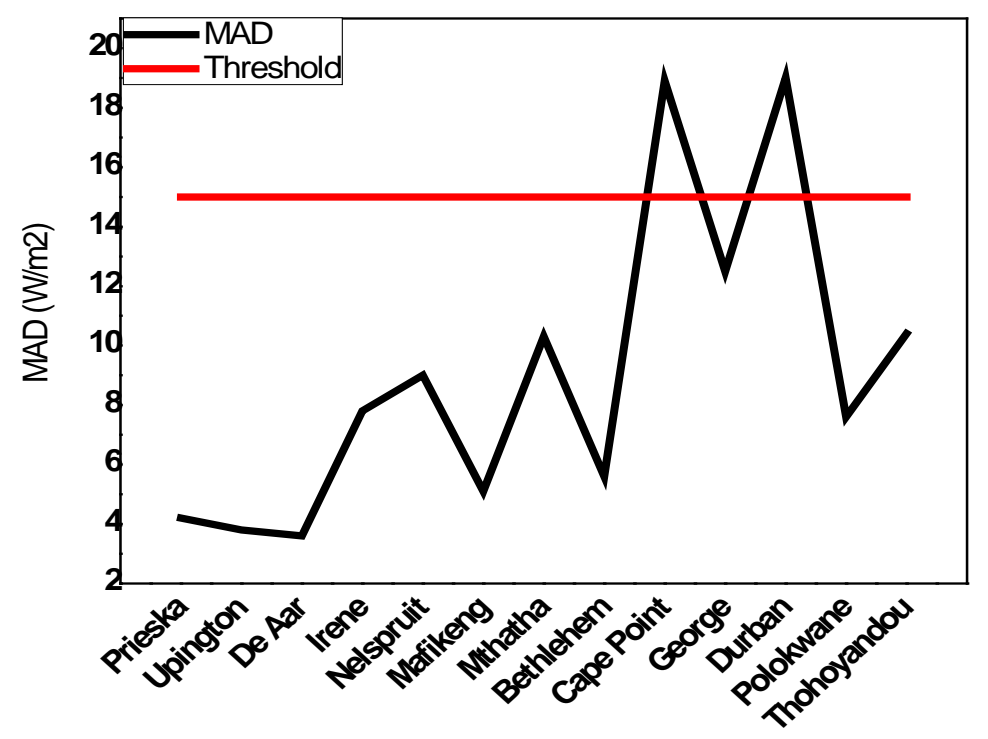

Figure 3: Monthly MAD values for the validation of the GHI estimates derived from the SARAH product for all locations. 
less than $8 \mathrm{Wm}^{-2}$ when compared to the SARAH GHI. On the other hand, Nelspruit (hot interior) reached a target accuracy threshold with MAD less than 10 $\mathrm{Wm}^{-2}$, while Thohoyandou (hot interior), George (temperature coastal) and Mthatha (Subtropical coastal) meet the validation threshold with MAD less than $15 \mathrm{Wm}^{-2}$.

\subsection{Diffuse fraction and clearness index}

The clearness index and diffuse fraction shown in Figure 4 depict higher values (near 1) of clearness index, implying a clear sky and calm atmosphere. In case of Upington and De Aar, clearness index averages were $>0.6$ throughout the year. The diffuse fraction of solar radiation was also calculated for all locations and found to vary from 0 to 1 . Higher val- ues indicate more aerosols and clouds. The values for diffuse fraction for Upington and De Aar were always $<0.3$ in all months, indicating suitability of the locations for solar energy prospecting.

\section{Conclusions}

The Baseline Surface Radiation Network quality control (BSRN QC) tests proved to be effective and efficient in detecting errors at different stations.

- The overall average performance of the surface solar radiation dataset - Heliosat (SARAH) data record for the global horizontal irradiance (GHI) estimation for all the stations exhibited mean bias deviation of $-8.28 \mathrm{Wm}^{-2}$, mean absolute deviation of $9.06 \mathrm{Wm}^{-2}$, and root mean square deviation of $11.02 \mathrm{Wm}^{-2}$.
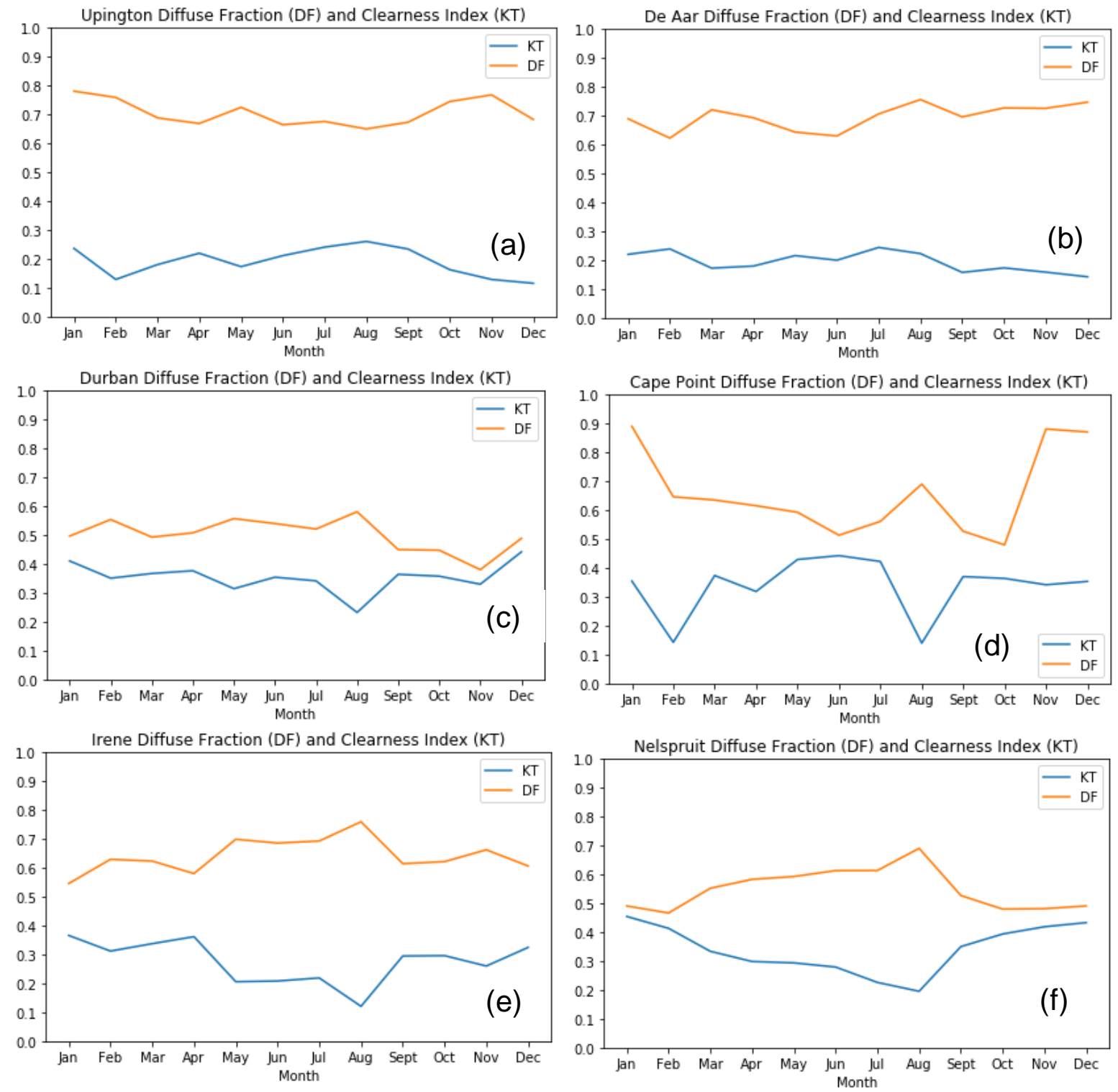

Figure 2: Monthly diffuse fraction and clearness indices for one station per climatic region: $(\mathrm{a})=$ Upington, (b) = De Aar, (c) = Durban, (d) = Cape Point, $(e)=$ Irene, $(f)=$ Nelspruit. 
- The SARAH estimates can provide the basis for further analysis, such as the one presented in this study on annual photovoltaic electricity production.

- The overall percentage performance of SAWS' solar radiation network based on BSRN QC procedures is $97.79 \%, 93.64 \%, 91.6 \%$ and $92.23 \%$ for long wave downward irradiance, GHI, diffuse horizontal irradiance and direct normal irradiance, respectively, demonstrating the potential value of SAWS solar resource database for practical and scientific applications in South Africa.

\section{Acknowledgements}

Part of the work presented here was carried out within the 'Solar resource mapping for South Africa' project funded by the Department of Science and Technology. South African Weather Service staff from regional offices are thanked for their continuous efforts in helping with station inspection, cleaning and maintenance. Baseline
Surface Radiation Network staff helped us with some answers related to the BSRN toolbox software operation. Dr Roland Vogt from the University of Basel provided us with the Interactive Data Visualisation BSRN program. $\mathrm{Mr}$ Louis van Hemert from SAWS helped with the FORTRAN 90 code to convert data from station-to-archive format, and SAWS staff in the Renewable Energy Application group gave their inputs in the daily operation of the radiometric network.

\section{Author roles}

Lucky Ntsangwane: Project initiator, conceptualisation of the research, data collection and analysis, writing of the manuscript.

Brighton Mabasa: Data collection and analysis, software setup and write-up.

Nosipho Zwane: Data collection and analysis.

Katlego Ncongwane: Data collection, software acquisition and initial setup.

Venkataraman Sivakumar: Editing of the manuscript, supervision, scientific and technical advice.

Joel Botai: Editing of the manuscript, supervision, scientific and technical advice.

\section{References}

[1] Jäger-Waldau, A. PV Status Report 2016. EUR 28159 EN. 2016. Joint Research Centre Science for Policy Report. EUR 28159 EN. JRC 103426.

[2] International Energy Agency. 2017 Analysis and forecast to 2022. International Energy Agency Publications.

[3] Sengupta, M., Habte, A., Gueymard, C., Wilbert, S. and Renné, D. 2017. Best practices handbook for the collection and use of solar resource data for solar energy applications, Second edition. National Renewable Energy Laboratory: Colorado, United States. https://doi.org/10.18777/ieashc-task46-2017-0001

[4] Antoñanzas-Torres, F., Sanz-Garcia, A., Martinez-de-Pison-Ascacibar, F.J. and Perpiñan-Lamiguiero, 0. 2013. Evaluation and improvement of empirical models of global solar irradiation: Case study northern Spain. Renewable Energy, 60, 604-614. https://doi.org/10.1016/j.renene.2013.06.008

[5] Meyer, A.J. and van Niekerk, J.L. 2015. Towards a verified DNI map for South Africa. In Third Southern African Solar Energy Conference, Kruger National Park, South Africa, 11-13 May.

[6] Brooks, M.J., du Clou, S., van Niekerk, W.L., Gauche, P., Leonard, C., Mouzouris, M.J., Meyer, R., van der Westhuizen, N., van Dyk, E.E. and Vorster, F.J. 2015. SAURAN: A new resource for solar radiometric data in Southern Africa. Journal of Energy in Southern Africa, 26, 2-10. https://doi.org/10.17159/2413-3051/2015/v26i1a2208

[7] Ciolkosz, D. SASRAD. 2009. An hourly-timestep solar radiation database for South Africa. Journal of Energy in Southern Africa, 20, 25-34. https://doi.org/10.17159/2413-3051/2009/v20i1a3299

[8] Ineichen, P., Barroso, C.S., Geiger, B., Hollmann, R., Marsouin, A. and Müller, R. 2009. Satellite application facilities irradiance products: Hourly time step comparison and validation over Europe. International Journal of Remote Sensing, 30, 5549-5571. https://doi.org/10.1080/01431160802680560

[9] Conradie, D.C.U. 2012. South Africa's Climatic Zones: Today, Tomorrow, International Green Building Conference and Exhibition Future Trends and Issues Impacting on the Built Environment, Sandton, South Africa, 25-26 July.

[10] Lee, C. 2014. Baseline Surface Radiation Network, World Climate Research Programme, An overview of the requirements and operational issues. Derived from the BSRN Operations Manual Version 2.1, Customer Services Specialist, Kipp \& Zonen B.V.

[11] South African National Standard 204. Energy efficiency in buildings, Part 1: General requirements. South African Bureau of Standards. Available online: https://www.sabs.co.za/Sectors-and-Services/Services/Energy/energy_sp.asp (Accessed on 15 September 2013).

[12] Urraca, R., Gracia-Amillo, A.M., Huld, T., Martinez-de-Pisona, F.J., Trentmanne, J., Lindforsf, A.V., Riihelaf, A. and Sanz-Garcia, A. 2017. Quality control of global solar radiation data with satellite-based products. Solar Energy, $158,49-62$. https://doi.org/10.1016/j.solener.2017.09.032 
[13] Huld, T., Mueller, R. and Gambardella, A. 2012. A new solar radiation database for estimating PV performance in Europe and Africa. Solar Energy, 86, 1803-1815. https://doi.org/10.1016/i.solener.2012.03.006

[14] Gracia-Amillo, A., Huld, T. and Müller, R. 2014. A new database of global and direct solar radiation using the eastern meteosat satellite, models and validation. Remote Sensing, 6, 8165-8189. https://doi.org/10.3390/rs6098165

[15] Müller, R., Matcoukas, C., Gratzki, A., Behr, H.D. and Hollmann, R. 2009. The CM-SAF Operational scheme for the satellite based retrieval of solar Surface irradiance - A LUT based eigenvector hybrid approach. Remote Sensing and Environment, 113, 1012-1024. https://doi.org/10.1016/j.rse.2009.01.012

[16] Inness, A., Baier, F., Benedetti, A., Bouarar, I., Chabrillat, S., Clark, H., Clerbaux, C., Coheur, P., Engelen, R. J., Errera, Q., Flemming, J., George, M., Granier, C., Hadji-Lazaro, J., Huijnen, V., Hurtmans, D., Jones, L., Kaiser, J. W., Kapsomenakis, J., Lefever, K., Leitão, J., Razinger, M., Richter, A., Schultz, M. G., Simmons, A. J., Suttie, M., Stein, O., Thépaut, J.-N., Thouret, V., Vrekoussis, M., Zerefos, C., and the MACC team. 2013. The MACC reanalysis: An 8-year data set of atmospheric composition. Atmospheric Chemistry and Physics, 13, 4073-4109. https://doi.org/10.5194/acp-13-4073-2013

[17] Müller, R., Pfeifroth, U. and Träger-Chatterjee, C. 2015. Towards optimal aerosol information for the retrieval of solar surface radiation using Heliosat. Atmosphere, 6, 863-878. https://doi.org/10.3390/atmos6070863

[18] Müller, R., Pfeifroth, U., Träger-Chatterjee, C., Trentmann, J. and Cremer, R. 2015. Digging the METEOSAT treasure -3 decades of solar surface radiation. Remote Sensing, 7, 8067-8101.

[19] Riihelä, A.; Carlund, T.; Trentmann, J.; Müller, R. and Lindfors, A.V. 2015. Validation of CM SAF surface solar radiation datasets over Finland and Sweden. Remote Sensing, 7, 6663-6682. https://doi.org/10.3390/rs70606663

[20] Urraca, R.; Gracia-Amillo, A.M.; Koubli, E., Huld, T.; Trentmann, J.; Riihelä, A.; Lindfors, A.V.; Palmer, D.; Gottschalg, R. and Antonanzas-Torres, F. 2017. Extensive validation of CM SAF surface radiation products over Europe. Remote Sensing Environment, 199, 171-186. https://doi.org/10.1016/j.rse.2017.07.013

[21] Žák, M.; Mikšovský, J. and Pišoft, P. 2015. CMSAF radiation data: New possibilities for climatological applications in the Czech Republic. Remote Sensing, 7, 14445-14457. https://doi.org/10.3390/rs71114445

[22] Long, C.N. and Dutton, E.G. BSRN global network recommended QC tests, V2.0. Available online: http://epic.awi.de/30083/1/BSRN_recommended_QC_tests_V2.pdf (Accessed on 02 December 2017).

[23] Roesch, A., Wild, M., Ohmura, A., Dutton, E.G., Long, C.N. and Zhang, T. 2011. Assessment of BSRN radiation records for the computation of monthly means. Atmospheric Measurement Technics, 4, 339-354. https://doi.org/10.5194/amt-4-339-2011

[24] Thomas, C., Saboret, L., Wey, E., Blanc, P. and Wald, L. 2016. Validation of the new Helioclim-3 version 4 real-time and short-term forecast service using 14 BSRN Stations. Advisory Scientific Research, 13, 129-136. https://doi.org/10.5194/asr-13-129-2016

[25] Schulz, J., Albert, P., Behr, H.-D., Caprion, D., Deneke, H., Dewitte, S., Dürr, B., Fuchs, P., Gratzki, A., Hechler, P., Hollmann, R., Johnston, S., Karlsson, K.-G., Manninen, T., Müller, R., Reuter, M., Riihelä, A., Roebeling, R., Selbach, N., Tetzlaff, A., Thomas, W., Werscheck, M., Wolters, E., and Zelenka, A. 2009. Operational climate monitoring from space: THE EUMETSAT Satellite Application Facility on Climate Monitoring (CM-SAF). Atmospheric Chemistry and Physics, 9, 1687-1709. https://doi.org/10.5194/acp-9-1687-2009

[26] Sengupta, M., Habte, A., Kurtz, S., Dobos, A., Wilbert, S., Lorenz, E., Stoffel, T., Renné, D., Gueymard, C., Myers, D., Wilcox, S., Blanc, P. and Perez, R. 2015. Best practices handbook for the collection and use of solar resource data for solar energy applications, National Renewable Energy Laboratory (NREL): Colorado, United States. https://doi.org/10.18777/ieashc-task46-2015-0001

[27] Lorenz, E., Kühnert, J., Heinemann, D., Nielsen, K.P., Remund, J. and Müller, S.C. 2015. Comparison of irradiance forecast based on numerical weather prediction models with different spatio-temporal resolutions. In 31st EU PVSEC in Hamburg, Germany. https://doi.org/10.1002/pip.2799

[28] Posselt, R., Mueller, R.W., Stockli, R. and Trentmann, J. 2012. Remote sensing of solar surface radiation for climate monitoring - the CM-SAF retrieval in international comparison, Remote Sensing and Environment, 118,186198. https://doi.org/10.1016/j.rse.2011.11.016

[29] Gracia-Amillo, A., Ntsangwane, L., Huld, T. and Trentmann, J. 2018. Comparison of satellite-retrieved high-resolution solar radiation datasets for South Africa. Journal of Energy in Southern Africa, 29, 63-76. https://doi.org/10.17159/2413-3051/2018/v29i2a3376 